\title{
Secreted production of assembled Norovirus virus-like particles from Pichia pastoris
}

\author{
Jaime Tomé-Amat, Lauren Fleischer, Stephanie A Parker, Cameron L Bardliving and Carl A Batt
}

\begin{abstract}
Background: Norovirus virus-like particles (NoV VLPS) have recently been explored as potential vaccine platforms due to their ability to produce an effective immune response. Expression of the main structural protein, VP1, leads to formation of self-assembled particles with similar characteristics to the original virus. These NoV VLPs have been expressed in Escherichia coli, yeast and insect cells. Expression in E. coli and insect cells share downstream processing issues due to the presence of inclusion bodies or the need for numerous purification steps. NoV VLPs have also been produced in the yeast P. pastoris; however the protein was only expressed intracellularly.

Results: We have successfully expressed and secreted the VP1 protein in the novel P. pastoris strain, Bg11, using the methanol inducible pJ912 expression vector, containing the CDNA of NoV VP1. Expression of the VP1 protein in Bg11 was carried out in a $1.5 \mathrm{~L}$ bioreactor resulting in a total yield of NoV VLPs greater than $0.6 \mathrm{~g} / \mathrm{L}$. NoV VLPs obtained from the culture supernatant were purified via ion-exchange chromatography, resulting in particles with a purity over 90\%. The average size of the particles after purification was $40 \mathrm{~nm}$. Transmission electron microscopy was used to visualize the morphology of the particles and saliva-binding assay confirmed that the NoV VLPs bind to Histo-Blood Group Antigens (HBGA).

Conclusions: In this study we describe the expression and characterization of fully assembled Norovirus virus-like particles obtained from P. pastoris. The particles are similar in size, morphology and binding capacity, as previously described, for the original NoV. Our results detail the successful expression and secretion of VLPS in P. pastoris, improving their candidacy as a vaccine platform.
\end{abstract}

\section{Background}

NoV VLPs have emerged as a promising candidate for a vaccine platform due to their capacity to elicit a strong humoral and cellular immune response. Several NoV VLPs constructs have been developed through insertion of small antigenic epitopes into the NoV VLPs such as the $\mathrm{T}$ cell epitope of murine cytomegalovirus, the CD4+ $\mathrm{T}$ cell epitope of murine rotavirus VP6, and the M2 extracellular epitope of influenza virus. Studies of these constructs in mice demonstrated an increase in antibody response and immune system activation [1]. VP1 is the main structural protein of Norovirus, and it consists of 555 amino acids, with a molecular weight of approximately $60 \mathrm{kDa}$. The VP1 protein includes two distinct structural domains, $\mathrm{S}$ for shell and $\mathrm{P}$ for protruding. The $\mathrm{S}$ domain is comprised of the first 225 amino acids, and is essential for the formation of the icosahedrons. The $\mathrm{P}$

\footnotetext{
*Correspondence: jmt339@cornell.edu

Department of Food Science, Cornell University, Ithaca, NY 14853, USA
}

domain is further divided into two subdomains, which are involved in dimeric contacts that increase the stability of the capsid [2]. The P2 subdomain is responsible for receptor binding and immune reactivity [3]. X-ray crystallography studies show that 180 subunits of VP1 form a $\mathrm{T}=3$ icosahedral virion [4]. The expression of VP1 protein leads to the formation of virus-like particles by self-assembly and these particles are morphologically and antigenically similar to the infectious virus $[5,6]$.

Due to its particulate nature and repetitive ordered structure, NoV VLPs are highly immunogenic, enhancing immune activation by effector cells [7]. The repetitive antigenic epitopes lead to crosslinking of B cell immunoglobulin receptors and B cell activation [8-10]. NoV VLPs are optimal for dendritic cell uptake, activating innate and adaptive immune responses [11-13]. These features support NoV VLPs as an effective vaccine platform [11,14-16]. 
Since Noroviruses do not replicate in tissue culture, several expression systems have been studied for $\mathrm{NoV}$ VLPs production including Escherichia coli, P. pastoris, insect cells and transgenic plants [17-20]. Ease of strain development, scalability and product yield are important factors in selecting an expression system. While E. coli is a widely preferred system, protein complexity may present obstacles through the inability to perform posttranslational modifications in E. coli and the formation of inclusion bodies that need to be disrupted to form functional virions [21]. Thus, $P$. pastoris and insect systems are advantageous alternatives to $E$. coli expression [22]. To date, NoV VLPs production in insect cells has resulted in yields of approximately $100 \mathrm{mg} / \mathrm{L}$ [23-25] but the NoV VLPs are produced alongside enveloped baculovirus particles requiring more complex purification [26]. Insect cells expression also requires a complex growth medium and cell growth takes $18-24 \mathrm{~h}$ per division. $P$. pastoris medium is less complex, and has a significantly faster doubling time $(90 \mathrm{~min})$. P. pastoris is also easy to maintain, low-cost, easily scalable and has the ability to produce posttranslational modifications [27]. Another advantage of using the P. pastoris expression system is its ability to secrete the product into the culture media, resulting in a less complex purification process. The hepatitis B surface antigen was successfully expressed on a VLP platform in P. pastoris [28]. However, the VLPs were expressed intracellularly [20,28-31] compromising the final yield and increasing the complexity of the purification process [23,32,33].

In this report we describe, for the first time to date, the secretion of NoV VLPs in P. pastoris, with a yield over $0.6 \mathrm{~g} / \mathrm{L}$. The VLPs were expressed using controlled methanol induction, in a $1.5 \mathrm{~L}$ bioreactor and purified by anion exchange chromatography. These particles have been characterized and fully assembled virions are shown to be present in the medium during fermentation without evidence of cell lysis.

\section{Results}

\section{Expression and purification}

P. pastoris Bg11 cells were electroporated with $10 \mu \mathrm{g}$ of linearized plasmid containing the secretion $\alpha$-factor fused with the cDNA encoding the VP1 protein. Eight colonies were selected for further analysis. From these eight colonies, the colony with the highest protein expression, determined by western blot, was selected for a $1.5 \mathrm{~L}$ fermentation. A single colony was grown in $100 \mathrm{~mL}$ of BMGY as a preinoculum for the fermentation. Fermentation was initially grown in batch phase in medium with glycerol to increase biomass. The end of the batch phase was detected by a DO-spike (Figure 1A), after which protein expression was induced with methanol at a concentration of $2 \mathrm{~g} / \mathrm{L}$. Every $24 \mathrm{~h}$ an aliquot

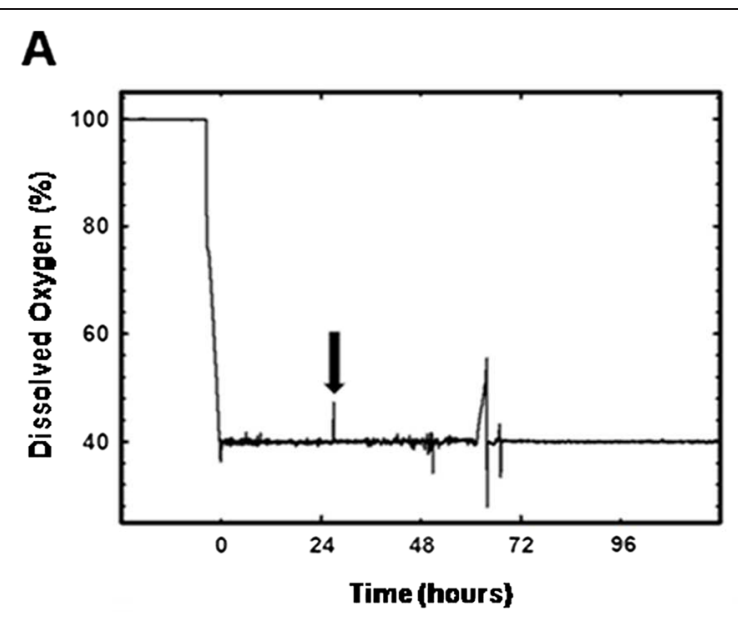

B
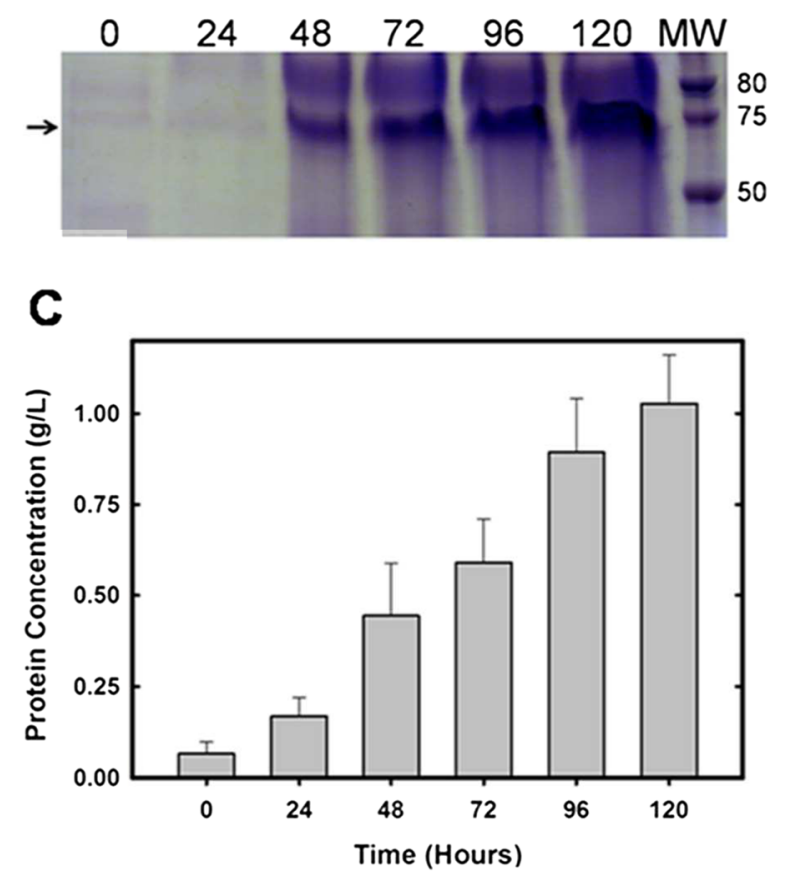

Figure 1 NoV VLPs production. A) On-line methanol control performance. Induction phase starts $24 \mathrm{~h}$ after inoculation. The arrow indicates beginning of methanol addition. B) Every $24 \mathrm{~h}$ aliquots were taken from the fermentation media. Cells and supernatant were separated by centrifugation and $10 \mu \mathrm{l}$ of each supernatant sample was loaded into a SDS-PAGE gel. C) Protein concentration was determined for each aliquot, taken every 24 h, by Bradford.

was taken from the bioreactor and dry cell weight was recorded and the culture supernatant was stored at $4^{\circ} \mathrm{C}$. Protein expression was analyzed via SDS-PAGE gel (Figure 1B), and total protein concentration was measured by Bradford (Figure $1 \mathrm{C}$ ). The final dry cell weight for the fermentation was $300 \mathrm{~g} / \mathrm{L}$. After $120 \mathrm{~h}$ of methanol induction, the extracellular medium was collected and the NoV VLPs were purified using ion-exchange 
chromatography, on a Sepharose Q XL column. A step gradient was used to elute the NoV VLPs. The chromatogram showed three major elution peaks (Figure 2), where NoV VLPs elute in the peak between 0.1-0.2 M $\mathrm{NaCl}$, as expected $[34,35]$. The elution fractions containing the NoV VLPs were pooled together and analyzed. The SDS-PAGE gel showed a band at $62 \mathrm{kDa}$ corresponding to the molecular weight of the VLP protein. Western Blot using the anti-NoV serum also revealed a positive band at $62 \mathrm{kDa}$ confirming the expression of the full-length VP1 protein (Figure 2). Protein concentration was over $1 \mathrm{~g} / \mathrm{L}$ in the fermentation supernatant, and approximately $600 \mathrm{mg}$ after protein purification.

\section{Cell lysis}

The band detected in the Western Blot at $62 \mathrm{kDa}$ with antiNoV serum suggests secretion of the VP1 protein, but to confirm the absence of appreciable cell lysis an intracellular marker, $\alpha$-glucosidase, was measured in the culture media [36]. A reference curve using lysed cells was constructed to correlate the activity of this enzyme with the volume of lysed cells. After reacting with pNPG, absorbance was measured at $405 \mathrm{~nm}$ (Data not shown). Subsequently, a $500 \mu \mathrm{l}$ sample was taken from the bioreactor, and cells and media were separated by centrifugation. Cells were lysed, and both lysate and media were analyzed. The results were $1.1 \pm 0.021 \mathrm{UA}$ for the lysate and $0.07 \pm 0.003$ UA for the media (Figure 3A). Based upon the activity, the amount of cell lysis was less than
$7 \%$ of the total cell population. Afterwards, a sample of lysed cells from the fermentation and a sample of the supernatant were used for SDS-PAGE and Western Blot analysis using antiNoV serum. The sizes of the bands observed in the Western Blot were $62 \mathrm{KDa}$ for the supernatant sample and $77 \mathrm{KDa}$ for the lysed cell sample (Figure 3B) suggesting the presence of the $\alpha$-factor not correctly cleaved in the lysed cells and the correct cleavage of the $\alpha$-factor in the secreted VP1 protein.

\section{Saliva-VLP binding assay}

To confirm the activity of $P$. pastoris expressed NoV VLPs, a purified sample was tested for epitope binding in saliva. NoV VLPs have been shown to recognize and bind epitopes $\mathrm{H}, \mathrm{A} / \mathrm{B}$, and $\mathrm{O}$-secretor types in saliva samples [33,37]. For this study saliva A-phenotype was used in the binding assay and the results confirmed binding of the VLPs to the saliva samples (Figure 4). The $\mathrm{ID}_{50}$ obtained in the ELISA was $0.8 \mathrm{ng} / \mu \mathrm{L}$.

\section{Size and morphology characterization by TEM and DLS}

The particle size and morphology of the P. pastoris expressed NoV VLPs were characterized following the fermentation and purification. To determine the average size of the particles during the process, different samples were studied using DLS. Samples from the culture media and purification were concentrated using an Amicon Ultra Membrane (Millipore) for DLS measurements. From the purified pool, an aliquot was dialyzed against
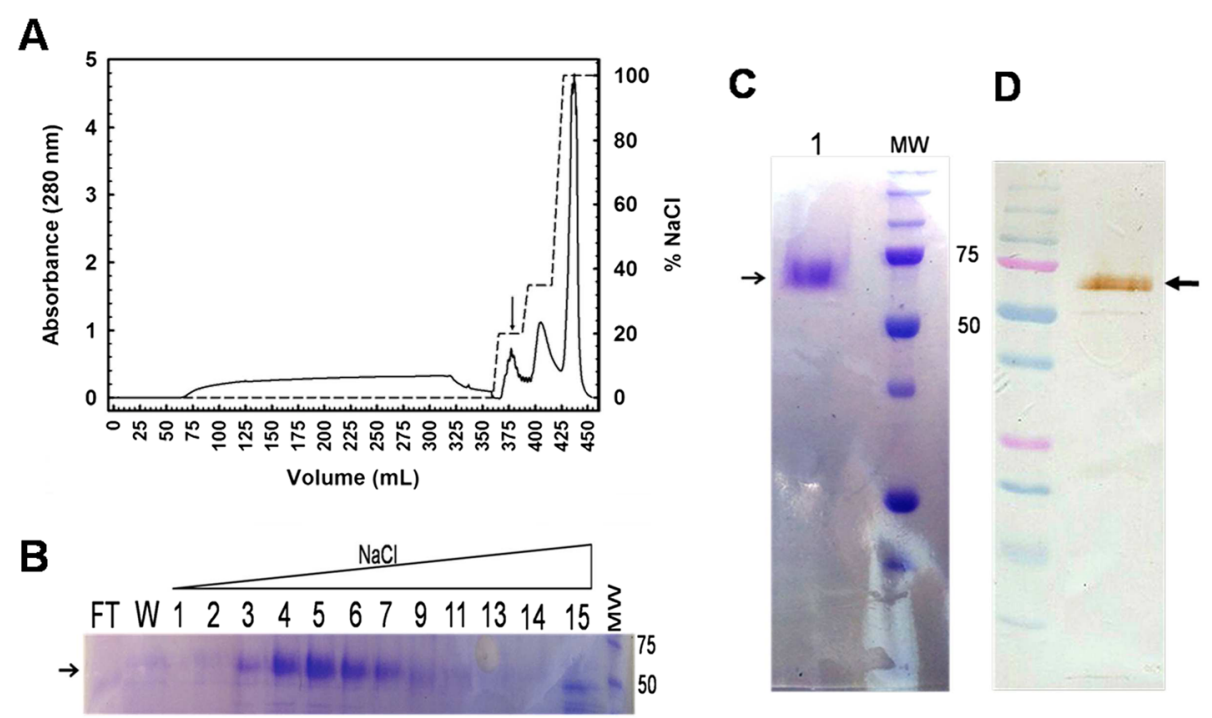

Figure 2 NoV VLPs purification. Time course for VLP production. Coomasie brilliant blue stained SDS-PAGE of production and purification of the VP1 protein. A) Chromatogram of VLP purification. Solid line represents absorbance at $280 \mathrm{~nm}$ and dashed line percentage of $\mathrm{NaCl}$ in the buffer. The arrow indicates the elution peak of the VLPs. B) Aliquots from ion exchange purification. The numbers correspond to the aliquot number during the $\mathrm{NaCl}$ gradient. After purification, pools 4 to 7 where dialyzed against BA $50 \mathrm{mM}$ and lyophilized. Part of the lyophilized protein was resuspended in PBS. C) and D) SDS-PAGE and Western Blot using anti-NoV from this pool are shown, respectively. In each gel the molecular weights are represented with the correspondent value. Arrows indicate the mobility of the VP1 band in the SDS-PAGE. 


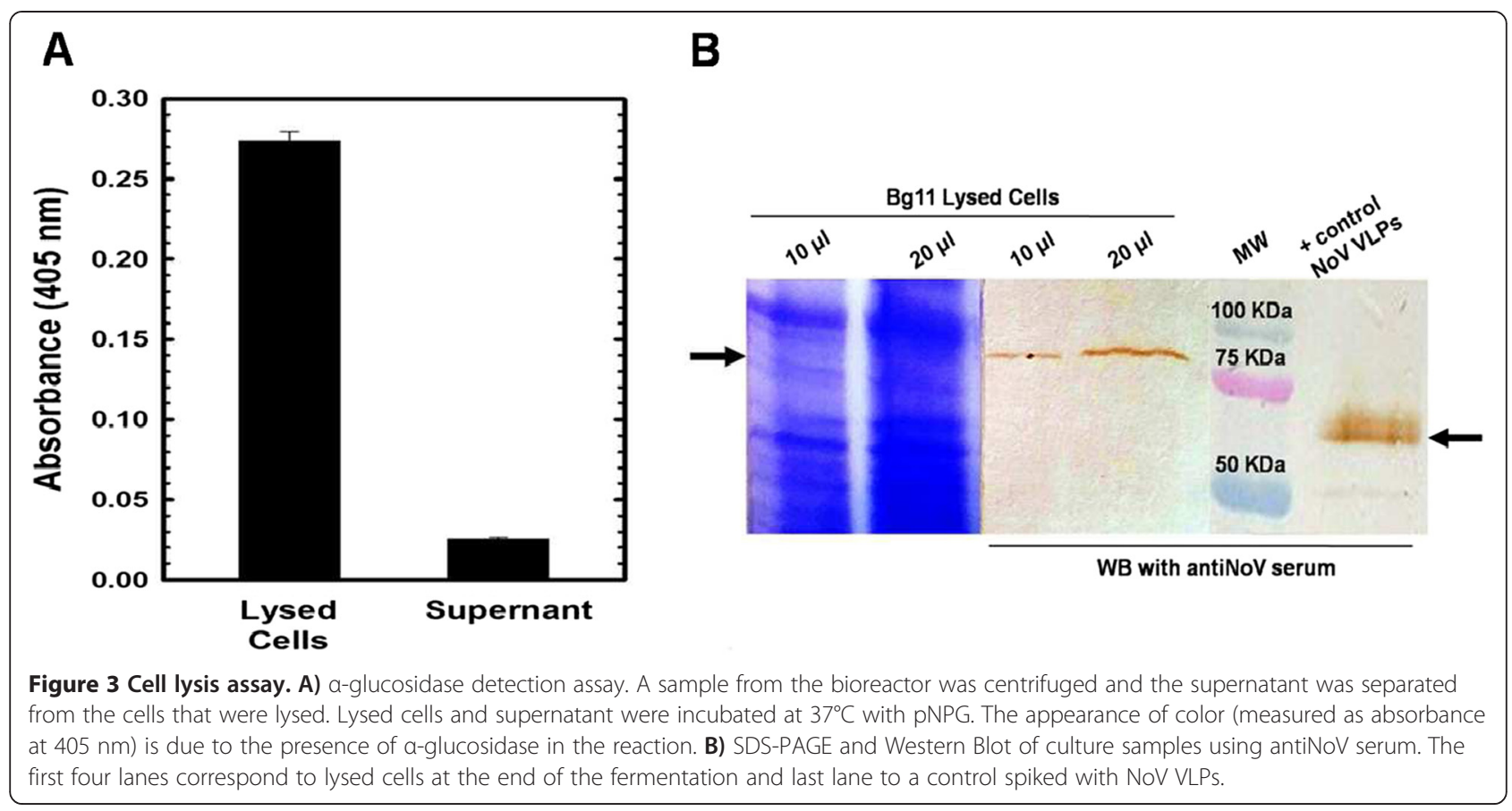

$50 \mathrm{mM}$ ammonium bicarbonate $\mathrm{pH} 6.0$ and then lyophilized. Figure 5 shows the average size of the particles during the fermentation $(\approx 107 \mathrm{~nm})$, chromatography $(\approx 70 \mathrm{~nm})$ and resuspended lyophilized product $(\approx 40 \mathrm{~nm})$. Furthermore, the dotted line in Figure 5 depicts the average size of the population after having been stored at $4^{\circ} \mathrm{C}$ for one week, indicating particle aggregation at low temperatures, as described previously [38]. The particle size and morphology was further examined via transmission electronic microscopy (Figure 6). Figure 6A shows particles present,

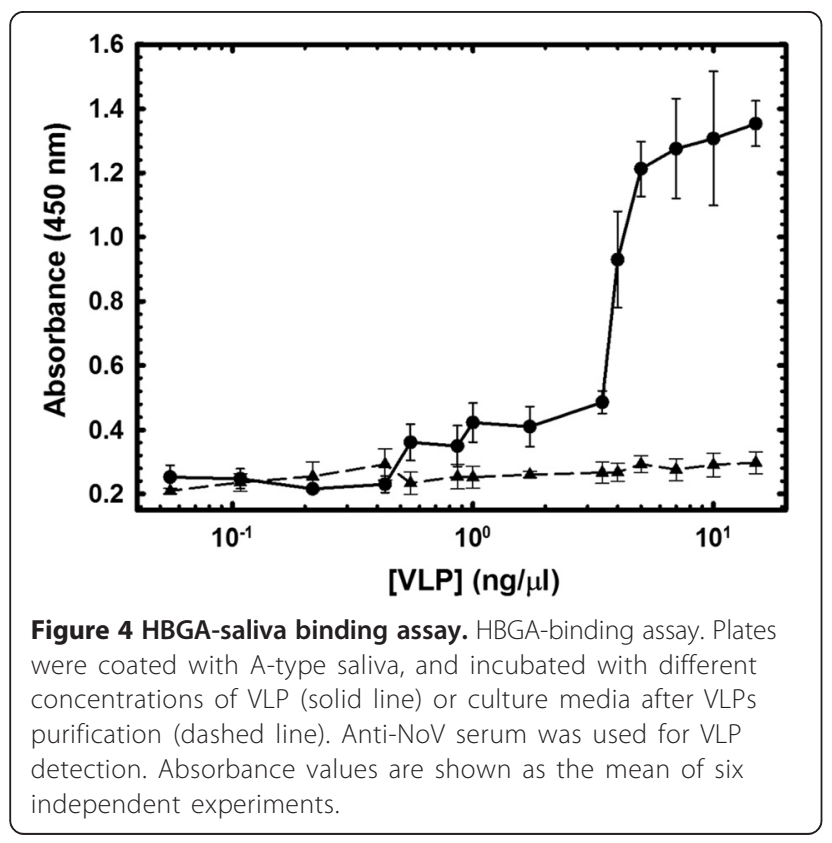

during the fermentation, in the culture supernatant with a range of sizes (40-100 $\mathrm{nm}$ ), corresponding with the data obtained by DLS. TEM images display the morphology of the NoV VLPs after chromatography in Figure 6B and C. Figure $6 \mathrm{D}$ represents a zoomed-in view of one of the particles after purification.

\section{Discussion}

In this study we report a method for the production of fully assembled NoV VLPs with high yield from a recombinant expression system. Several expression systems have been studied for this purpose, where insect cells are the preferred system for NoV VLPs expression $[11,23,35,38]$. The yield reported for this system is on the order of $100 \mathrm{mg} / \mathrm{L}$ of culture [23,25]. Yields were increased using $E$. coli, but this system presents drawbacks including lack of post-translational modifications, a deficiency in the formation of disulfide bonds, the formation of insoluble inclusion bodies, as well as the presence of endotoxin, as was observed when parvovirus B19, CCMV and CMV were expressed in E. coli [22]. Recently, there have been reports of expression in E. coli involving a new kind of NoV particles based on expression of only the P2 domain of the VP1 protein. This protein forms smaller particles, called p-particles. However, the relatively high endotoxin levels in the culture medium present a challenge for clinical trials. These $\mathrm{p}$ particles show similar binding patterns to those of the NoV VLPs when assayed against HBGA groups [23,32,36], but with one order of magnitude less binding than the NoV VLPs [23]. 


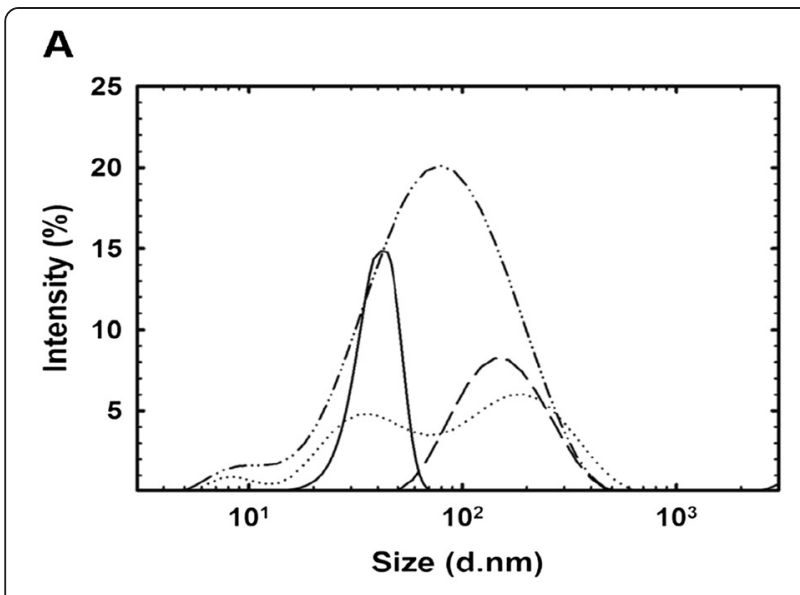

B

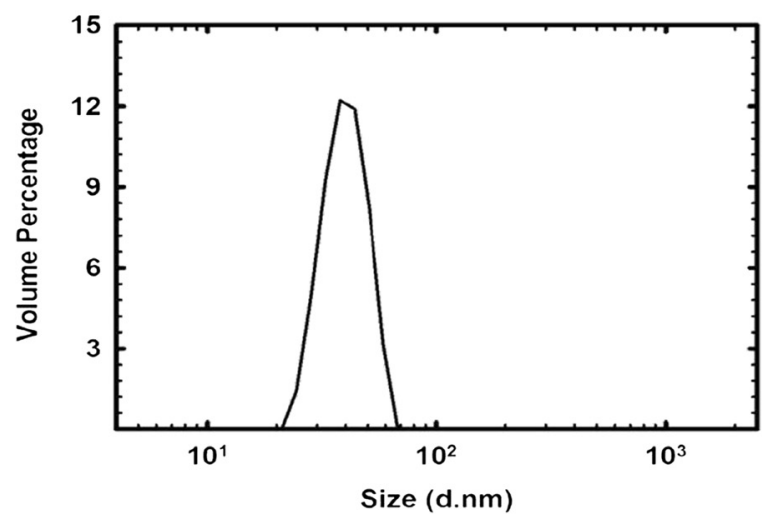

Figure $\mathbf{5}$ NoV VLPs dynamic light scattering assay. A) Particle size distribution samples measured by DLS from the fermentation (dashed line), after ion exchange chromatography (dash-dotted line) and after resuspension of the lyophilized protein (solid line). The dotted line corresponds to the same sample as the solid line does after one week at $4^{\circ} \mathrm{C}$. Results were calculated as an average of four measurements. B) Particle size distribution of a purified NoV VLPS sample expressed as volume percentage.

The $P$. pastoris expression system has advantages as it is widely acceptable for pharmaceutical applications and is easily scalable. Currently, there are no reports of NoV VLPs or p-particles obtained from the culture medium of $P$. pastoris. However, intracellular yields on the order of $10 \mathrm{mg} / \mathrm{L}$ have been reported [20,30]. Prior studies of NoV VLPs expressed in $P$. pastoris confirm that the particles stimulate systemic and mucosal immunity in mice [31]. Our work is the first to describe the production of fully assembled NoV VLPs obtained directly from the culture medium. Purification of the NoV VLPs was carried out using ion-exchange chromatography [34]. Other studies have compared several systems for VLP purification $[11,36,38]$, such as $\mathrm{CsCl}$ and ultracentrifugation, which are well known for achieving high purity levels. However, this method of purification is not easily scaled for larger volumes. Ion-exchange chromatography was selected due to its previous success with NoV VLPs purification, as well as its scalability for large-scale production and purification $[39,40]$.

The NoV VLPs reported here have binding characteristics similar to previously reported NoV VLPs [20,23]. A saliva-binding assay confirmed that the NoV VLPs produced in P. pastoris were correctly assembled, as indicated by a binding pattern comparable to earlier reports [38]. The $\mathrm{ID}_{50}$ obtained with NoV VLPs after purification is $0.8 \mathrm{ng} / \mu \mathrm{L}$, in accordance with previous reported values $(\approx 0.3 \mathrm{ng} / \mu \mathrm{L})[23,34]$. Additionally, DLS and TEM analysis of particle size and morphology are highly similar to those of previous reports [20,34], and confirmed the presence of NoV VLPs in the fermentation supernatant and after purification by ion-exchange chromatography. The average diameter of the NoV VLPs in the bioreactor (>60 nm) could be explained by the high salt concentration in the media, which has been shown to affect the particle size, as described with HPV VLPs expression in P. pastoris [41]. Aggregation of the VLPs could be prevented through lyophilization, the use of detergents, sorbitol, or other buffers [20,41,42].

Further characterization of NoV VLPs will require in vivo studies to examine the immunogenicity of the particles as well as examine their potential use as vaccine platforms. In addition, recent publications, regarding production in yeast, have showed that specific mutations in the $\alpha$-factor secretion signal enhanced the amount of secreted protein in the extracellular medium [43]. This presents a potential method of increasing production levels of NoV VLPs.

Implementation of NoV VLPs as a vaccine platform requires a scalable and well-characterized expression system for clinical applications. The work presented here shows, for the first time to date, the production of NoV VLPs using $P$. pastoris, obtained from the culture medium, containing a multi-cloning site for antigen insertion, with similar binding and morphological characteristics as NoV VLPs produced in other systems. This work is a step towards the development of NoV VLPs as vaccine platforms.

\section{Conclusions}

We have produced Norovirus virus-like particles from $P$. pastoris, using the novel strain, Bg11. The NoV VLPs were produced using a bioreactor and purified directly from the culture medium, via ion-exchange chromatography, with a final purity product over $90 \%$. The NoV VLPs were analyzed for capacity binding with the HistoBlood Group Antigen (HBGA). The results showed a binding pattern comparable to the original Norovirus. The morphology and size of the NoV VLPs were also studied using transmission electron microscopy and dynamic light scattering, confirming fully formed particles, 

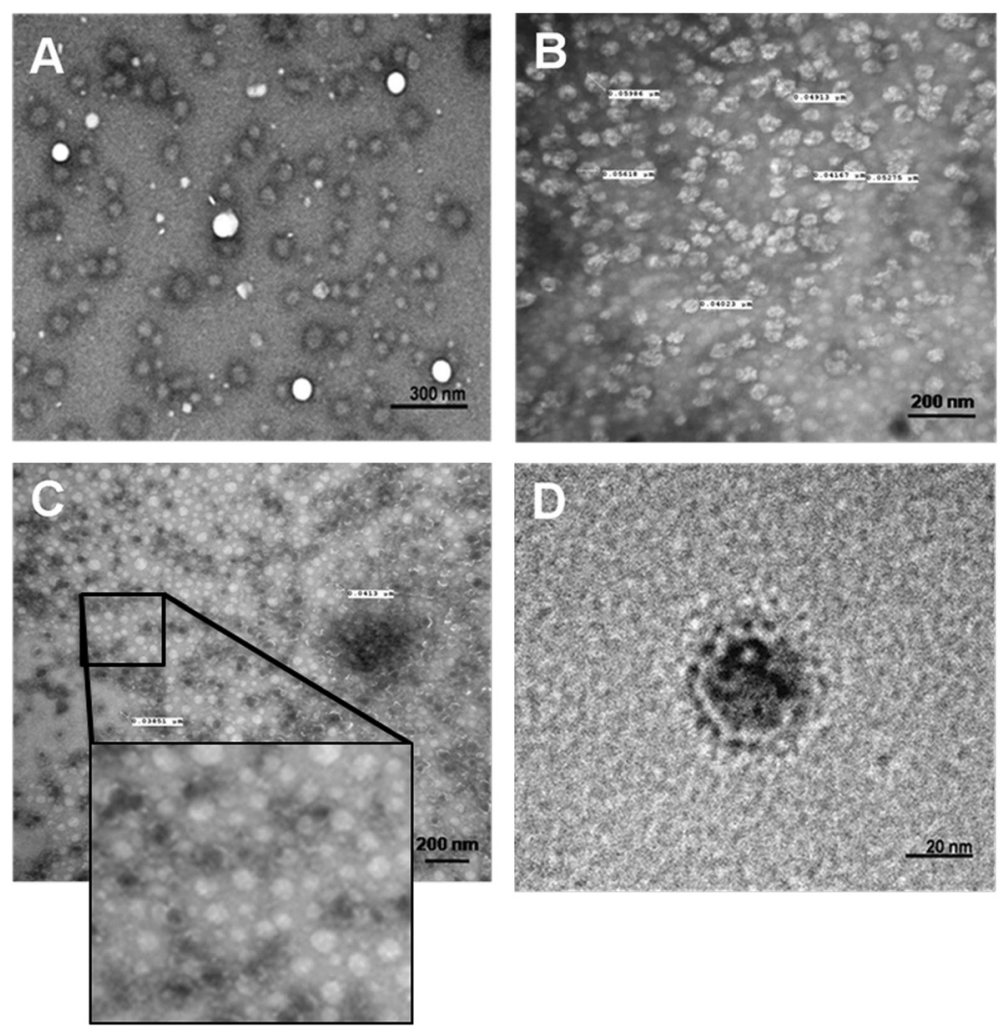

Figure 6 NoV VLPs transmission electronic microscopy. Images of VLP obtained using transmission electronic microscopy: A) corresponds with a concentrated sample from the culture supernatant during the fermentation, B) and C) corresponds to two different amplifications of sample after ion-exchange purification and $\mathbf{D})$ shows the morphology of a NoV virus like particle.

with an average size of $40 \mathrm{~nm}$. The particles also contain two multicloning sites inserted in the sequence of two external loops that could be used for antigen presentation. These production and purification systems described can be used for large-scale production of Norovirus virus-like particles as vaccine platform candidates.

\section{Materials and methods}

\section{Plasmid construction and organism}

The coding region for the NoV VP1 protein (GenBank acc. Number: AF080551) was received in the plasmid pJ912 from DNA2.0 (Menlo Park, CA, USA), and codon optimized for expression in $P$. pastoris. Two multicloning sites were inserted in the sequence to facilitate cloning into the two external loops of the NoV VLPs. The first multicloning site includes SpeI, NarI and FspI restriction sites, and the amino acid sequence corresponds with TSGGAGSAH, inserted between $\mathrm{A}_{296}$ and $\mathrm{T}_{306}$ of the VP1 sequence. The second Multicloning site includes PvuI, NotI and ScaI restriction sites, and the amino acid sequence corresponds with RSGGGRGST, inserted between $S_{382}$ and $D_{392}$ of VP1 sequence. The plasmid also contains the $\alpha$-factor secretion signal, and the gene for resistance to zeocin. The coding region of the NoV VP1 protein was cloned after the coding region for the $\alpha$-factor and the expression was regulated under the methanol inducible AOX1 promoter. P. pastoris Bg11 $\left(\mathrm{HIS}^{+}, \mathrm{Mut}^{\mathrm{S}}\right.$ ) was provided by Biogrammatics (Carlsbad, CA, USA) and transformed by electroporation with $10 \mu \mathrm{g}$ of linear plasmid [44].

P. pastoris transformants were grown on Yeast Extract Peptone Dextrose Medium (YPDS) plates containing: yeast extract $1 \%(\mathrm{w} / \mathrm{v})$, peptone $2 \%(\mathrm{w} / \mathrm{v})$, dextrose $2 \%(\mathrm{w} / \mathrm{v})$, sorbitol $1 \mathrm{M}$, agar $2 \%(\mathrm{w} / \mathrm{v})$ and zeocin $400 \mu \mathrm{g} / \mathrm{mL}$ and stored at $4^{\circ} \mathrm{C}$. For long-term storage, $P$. pastoris strains were stored at $-80^{\circ} \mathrm{C}[45,46]$.

\section{Protein expression}

Eight independent $P$. pastoris clones were tested for VLP secretion. After growth at $30^{\circ} \mathrm{C}$ for $24 \mathrm{~h}$ in $50 \mathrm{~mL}$ of buffered medium with glycerol for yeast (BMGY, [100 mM potassium phosphate, $\mathrm{pH} 6.0,1.34 \%(\mathrm{w} / \mathrm{v}) \mathrm{YNB}, 4 \times 10^{-5} \%$ $(\mathrm{w} / \mathrm{v})$ biotin, and $1 \%(\mathrm{v} / \mathrm{v})$ glycerol]), cells were harvested by centrifugation and resuspended in $25 \mathrm{~mL}$ of buffered medium with methanol for yeast (BMMY, [100 mM potassium phosphate, $\mathrm{pH} 6.0,1.34 \%(\mathrm{w} / \mathrm{v}) \mathrm{YNB}, 4 \times 10^{-5} \%$ $(\mathrm{w} / \mathrm{v})$ biotin, and $0.5 \%(\mathrm{v} / \mathrm{v})$ methanol]). The cultures were maintained at $30^{\circ} \mathrm{C}$ during $120 \mathrm{~h}$ with vigorous agitation 
and induced with methanol every $24 \mathrm{~h}$ to a final concentration of $0.5 \%(\mathrm{v} / \mathrm{v})$. The secreted protein in the supernatant was analyzed by $0.1 \%(\mathrm{w} / \mathrm{v})$ sodium dodecyl sulfate (SDS)-15\% (w/v) polyacrylamide gel electrophoresis (PAGE) and western blot. For the western blot, the proteins ran on an SDS-PAGE gel and were transferred onto a PDVF membrane (Millipore) and incubated at $37^{\circ} \mathrm{C}$ for $1 \mathrm{~h}$ in PBS with 5\% non-fat dry milk. Subsequently, a rabbit anti-NoV serum was used for immunological identification of the VP1 protein, and incubated for $2 \mathrm{~h}$ at $25^{\circ} \mathrm{C}$ with agitation at a ratio of $1: 2000$. The membrane was washed with PBS-Tween-20 0.5\% for $20 \mathrm{~min}$ and incubated for $1 \mathrm{~h}$ with GAR-HRP (1:3000) (BioRad). Color was developed using DAB (diaminobenzidine, Sigma), following the product instructions. The colony with the highest relative expression was selected for large-scale expression in the bioreactor.

\section{Fermentation}

Fermentation was carried out as described previously $[33,47]$. A single $P$. pastoris colony was grown in $5 \mathrm{~mL}$ of YPD $[1 \%(\mathrm{w} / \mathrm{v})$ yeast extract, $2 \%(\mathrm{w} / \mathrm{v})$ peptone, and $2 \%(\mathrm{w} / \mathrm{v})$ dextrose] overnight at $30^{\circ} \mathrm{C}$. This culture was used to inoculate $100 \mathrm{~mL}$ of BMGY. The new culture was grown in a baffled flask at $30^{\circ} \mathrm{C}$ while shaking until it reached an $\mathrm{OD}_{600}$ of $\sim 20$. This culture was used to inoculate $1.5 \mathrm{~L}$ of fermentation medium.

For the fermentation a Bioflo 3000 (New Brunswick Scientific, 2.5 L working volume) was used, interfaced with AFS-Biocommand Bioprocessing software version 2.6 (New Brunswick Scientific, Enfield, CT, USA) for data acquisition and control. The fermentation media consisted of $1.5 \mathrm{~L}$ of modified basal salts medium $\left[0.23 \mathrm{gL}^{-1} \mathrm{CaSO}_{4} \cdot 2 \mathrm{H}_{2} \mathrm{O}\right.$, $4.55 \mathrm{gL}^{-1} \mathrm{~K}_{2} \mathrm{SO}_{4}, 3.73 \mathrm{gL}^{-1} \mathrm{MgSO}_{4} \cdot 7 \mathrm{H}_{2} \mathrm{O}, 1.03 \mathrm{gL}^{-1}$ $\mathrm{KOH}$, and $6.68 \mathrm{~mL} \mathrm{~L}^{-1} \mathrm{H}_{3} \mathrm{PO}_{4}, 5 \%$ (v/v) glycerol] and $0.5 \mathrm{~mL}$ Antifoam 204 (Sigma, St. Louis, MO). For pH control, ammonium hydroxide $[15 \%(\mathrm{v} / \mathrm{v})]$ and phosphoric acid $[15 \%(\mathrm{v} / \mathrm{v})]$ were used. $\mathrm{PTM}_{1}$ trace salts (24 mM $\mathrm{CuSO}_{4}, 0.53 \mathrm{mM} \mathrm{NaCI}, 19.87 \mathrm{mM} \mathrm{MnSO}_{4}$, $0.83 \mathrm{mM} \mathrm{Na}_{2} \mathrm{MoO}_{4}, 0.32 \mathrm{mM}$ boric acid, $2.1 \mathrm{mM} \mathrm{CoCl}_{2}$, $0.15 \mathrm{mM} \mathrm{ZnCl}_{2}, 0.23 \mathrm{M} \mathrm{FeSO}_{4}$, and $0.82 \mathrm{mM}$ biotin) were aseptically added at $4.35 \mathrm{~mL} \mathrm{~L}^{-1}$ after sterilization prior to inoculation. Temperature and $\mathrm{pH}$ were maintained at $30^{\circ} \mathrm{C}$ and 6 , respectively. Dissolved oxygen (DO) was maintained at $40 \%$ of saturation and controlled by a DOcascade agitation (with a maximum speed of $1000 \mathrm{rpm}$ ), supplemented with pure oxygen when needed, and measured with an InPro6110/220 electrode (Mettler-Toledo GmbH, Germany).

The batch phase was maintained until all the glycerol was depleted, as indicated by a sharp rise in DO (DO spike). At that point the culture was fed with methanol (100\% methanol, with $12 \mathrm{~mL} \mathrm{PTM}_{1} \mathrm{~L}^{-1}$ ) and maintained at a constant concentration of $2 \mathrm{~g} / \mathrm{L}$. Every 24 hours, samples were collected and centrifuged in order to separate the culture supernatant from the pellet. The dry cell weight (DCW) was measured and the culture supernatant was kept for further analysis.

\section{Protein purification}

After the fermentation the culture was centrifuged at $4500 \mathrm{~g}$ at $4^{\circ} \mathrm{C}$ for $30 \mathrm{~min}$ to separate the supernatant from the pellet. The supernatant was filtered and dialyzed against $25 \mathrm{mM}$ potassium phosphate, $\mathrm{pH}$ 8.0, for anion-exchange chromatography. The chromatography was performed using a HiTrap Q XL $5 \mathrm{~mL}$ column (Amersham Biosciences, Pittsburgh, PA, USA) and an AKTA Explorer (Amersham Biosciences, Pittsburgh, PA, USA). The column was equilibrated with $25 \mathrm{mM}$ potassium phosphate, $\mathrm{pH} 8.0$, and after loading $50 \mathrm{~mL}$ of supernatant, the column was washed with the same buffer. NoV VLPs were eluted using a gradient of $25 \mathrm{mM}$ potassium phosphate, $\mathrm{pH} 8.0,1 \mathrm{M} \mathrm{NaCl}$. The chromatography fractions containing NoV VLPs were stored at $4^{\circ} \mathrm{C}$.

\section{Cell lysis}

Cell lysis was assayed through detection of $\alpha$-glucosidase using pNPG as described in literature [47-49]. A $4 \mathrm{mg} /$ $\mathrm{mL}$ solution of $\mathrm{pNPG}$ at was mixed in BSG (gelatin $0.1 \% \mathrm{w} / \mathrm{v}, \mathrm{NaCl} 0.85 \% \mathrm{w} / \mathrm{v}, \mathrm{KH}_{2} \mathrm{PO}_{4} 0.03 \%$ and $\mathrm{Na}_{2} \mathrm{HPO}_{4}$ $0.06 \% \mathrm{w} / \mathrm{v}$ ) and aliquots of different volumes were taken from the culture. After centrifugation at $4500 \mathrm{~g}$ at $4^{\circ} \mathrm{C}$ for $10 \mathrm{~min}$, the cell pellet was separated from the supernatant and lysed following the protocol described in EasySelect Pichia Expression Kit (Life technologies, Grands Island, NY). The lysates were mixed with BSG and $500 \mu \mathrm{l}$ aliquots were placed in $1.5 \mathrm{~mL}$ microfuge tubes containing $100 \mu \mathrm{l}$ of pNPG at $4 \mathrm{mg} / \mathrm{mL}$. These tubes were incubated at $37^{\circ} \mathrm{C}$ for 30 minutes, after which the reaction was stopped by the addition of $250 \mu \mathrm{l}$ of $1 \mathrm{M} \mathrm{Na}_{2} \mathrm{CO}_{3}$. Finally, the absorbance was measured at $405 \mathrm{~nm}$. An aliquot from the fermentation was centrifuged under the same conditions as described above, and the supernatant was separated from the pellet and filtered by $0.22 \mu \mathrm{m}$ to eliminate any cellular debris. The same protocol was performed on the fermentation sample and OD at $405 \mathrm{~nm}$ was measured. All the negative controls were developed with the assay and the background was subtracted from the results. Each point represents the average of three independent experiments.

\section{Particle size analysis}

The size of the NoV VLPs was analyzed with dynamic light scattering (DLS). Suspensions of the NoV VLPs were prepared using $25 \mathrm{mM}$ potassium phosphate buffer, $\mathrm{pH}$ 8.0, as dispersant and then transferred to $400 \mu \mathrm{L}$ disposable sizing cuvettes. DLS measures the diffusion of the particles 
moving under Brownian motion using a Zetasizer NanoZS (Malvern Instruments Ltd, Worcestershire, UK). The results were calculated as the average of six consecutive measurements recorded at $25^{\circ} \mathrm{C}$. Pre-determined viscosity and refractive index values were used in particle size calculations. The intensity and volume counts were plotted against particle size for each of the virus particle suspensions.

\section{Transmission Electronic Microscopy (TEM)}

Purified NoV VLPs were loaded onto copper mesh grids (Electron Microscopy Sciences, Fort Washington, PA) and stained with $1.5 \%$ Uranyl Acetate. The samples were imaged using a F20 FEI Technai $200 \mathrm{kV}$ field transmission electron microscope at the Cornell Center for Materials Research. Images were taken with a Gatan Orius dualscan CCD camera at 1-3 s exposure time.

\section{Saliva-VLP binding assay}

A $5 \mathrm{~mL}$ sample of human saliva phenotype A was diluted 1:1000 with $\mathrm{PBS}$, boiled at $100^{\circ} \mathrm{C}$ for $5 \mathrm{~min}$ to denature potential anti-NoV antibodies and centrifuged at $7000 \mathrm{~g}$ for $10 \mathrm{~min}$. From the supernatant, $100 \mu \mathrm{l} /$ well were used to coat a 96-well microtiter plate, which incubated overnight at room temperature. NoV VLPs at different concentrations were added to the wells and incubated for $2 \mathrm{~h}$ at room temperature, after which the plate was blocked with 5\% non-fat dry milk in PBS for $2 \mathrm{~h}$ at room temperature. The NoV VLPs were detected using an antiNoV serum (1:1000) for $1.5 \mathrm{~h}$ at room temperature, followed by GAR-HRP (1:3000) (BioRad) for another hour at room temperature. Color was developed using TMB Substrate Kit (Thermo Scientific), and the OD was measured at $450 \mathrm{~nm}$ using a Tecan GENios. Six independent experiments were conducted for each concentration point, and the highest VLP concentration was used for secondary control without saliva. Other secondary controls with the secondary antibodies were also carried out using the assay. The data are presented as the average of the results obtained for each well after background subtraction.

\footnotetext{
Abbreviations

DLS: Dynamic light scattering; GAR: Goat anti-rabbit; HBGA: Histo-Blood Group Antigens; NoV: Norovirus; PBS: Phosphate buffered saline;

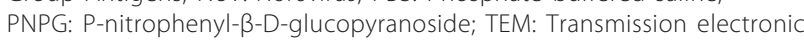
microscopy; VLPs: Virus-like particles.
}

\section{Competing interests}

The authors declare that they have no competing interests.

\section{Authors' contributions}

JT-A, planned and performed experiments, analyzed data and wrote the paper. LF, performed experiments, analyzed data and wrote the paper. SAP, performed experiments, analyzed data and wrote the paper. CLB, performed experiments, analyzed data and wrote the paper. CAB, planned experiments, analyzed data and wrote the paper. All authors read and approved the final manuscript.

\section{Acknowledgments}

This work was supported by the Cornell University Ludwig Institute for Cancer Research Partnership, and made use of the Cornell Center for Materials Research Shared Facilities supported through the NSF MRSEC program (DMR-1120296). The authors thank Dr. Knut Madden for providing P. pastoris Bg11 strain, Dr. Xi Jiang and Dr. Ming Xia for providing anti-NoV serum, and Dr. Gregory Salamo for obtaining TEM images of NoV VLPS samples.

Received: 25 May 2014 Accepted: 1 September 2014

Published: 10 September 2014

\section{References}

1. Tan M, Xia M, Huang PW, Wang LY, Zhong WM, McNeal M, Wei C, Jiang X: Norovirus $\mathrm{P}$ particle as a platform for antigen presentation. 4th Vaccine and Isv Annual Global Congress 2011, 4:19-26.

2. Hardy ME: Norovirus protein structure and function. FEMS Microbiol Lett 2005, 253:1-8.

3. Tan M, Huang PW, Meller J, Zhong WM, Farkas T, Jiang X: Mutations within the P2 domain of norovirus capsid affect binding to human histo-blood group antigens: evidence for a binding pocket. J Virol 2003, 77:12562-12571.

4. Prasad BW, Hardy ME, Dokland T, Bella J, Rossmann MG, Estes MK: X-ray crystallographic structure of the Norwalk virus capsid. Science 1999, 286:287-290.

5. Jiang X, Matson DO, Ruizpalacios GM, Hu J, Treanor J, Pickering LK: Expression, self-assembly, and antigenicity of a snow mountain agent-like calicivirus capsid protein. J Clin Microbiol 1995, 33:1452-1455.

6. Vongpunsawad S, Prasad BW, Estes MK: Norwalk virus minor capsid protein VP2 associates within the VP1 shell domain. J Virol 2013, 87:4818-4825.

7. Jennings GT, Bachmann MF: Coming of age of virus-like particle vaccines. Biol Chem 2008, 389:521-536.

8. Chackerian B: Virus-like particles-flexible platforms for vaccine development. Expert Rev Vaccines 2007, 6:381-390.

9. Deml L, Speth C, Dierich MP, Wolf H, Wagner R: Recombinant HIV-1 Pr55 (gag) virus-like particles: potent stimulators of innate and acquired immune responses. Mol Immunol 2005, 42:259-277.

10. Grgacic EVL, Anderson DA: Virus-like particles: passport to immune recognition. Methods 2006, 40:60-65.

11. Blazevic V, Lappalainen S, Nurminen K, Huhti L, Vesikari T: Norovirus VLPS and rotavirus VP6 protein as combined vaccine for childhood gastroenteritis. Vaccine 2011, 29:8126-8133.

12. Fang $H$, Tan $M, X i a ~ M$, Wang $L H$, Jiang $X$ : Norovirus $P$ particle efficiently elicits innate, humoral and cellular immunity. Plos One 2013, 8:e63269.

13. Fifis T, Gamvrellis A, Crimeen-Irwin B, Pietersz GA, Li J, Mottram PL, McKenzie IFC, Plebanski M: Size-dependent immunogenicity: therapeutic and protective properties of nano-vaccines against tumors. J Immunol 2004, 173:3148-3154.

14. Frey ST JJ, Atmar RL: Dose Escalation Trial of the Safety and Immunogenicity of a Bivalent Norovirus Virus-Like Particle Vaccine Administered by the Intramuscular Route. In 49th Annual Meeting of the Infectious Disease Society of America (IDSA); Boston, MA, USA; 2011.

15. Richardson C, Bargatze RF, Goodwin R, Mendelman PM: Norovirus virus-like particle vaccines for the prevention of acute gastroenteritis. Expert Rev Vaccines 2013, 12:155-167.

16. Treanor JF S, GormLey R: Safety and Immunogenicity of an Intramuscular Norovirus VLP Vaccine. In 52nd Interscience Conference on Antimicrobial Agents and Chemotherapy; San Francisco, CA, USA. 2012.

17. Mason HS, Ball JM, Shi JJ, Jiang X, Estes MK, Arntzen CJ: Expression of Norwalk virus capsid protein in transgenic tobacco and potato and its oral immunogenicity in mice. Proc Natl Acad Sci U S A 1996, 93:5335-5340.

18. Santi L, Batchelor L, Huang Z, Hjelm B, Kilbourne J, Arntzen CJ, Chen Q, Mason HS: An efficient plant viral expression system generating orally immunogenic Norwalk virus-like particles. Vaccine 2008, 26:1846-1854.

19. Thorne LG, Goodfellow IG: Norovirus gene expression and replication. J Gen Virol 2014, 95:278-291.

20. Xia M, Farkas T, Jiang X: Norovirus capsid protein expressed in yeast forms virus-like particles and stimulates systemic and mucosal immunity in mice following an oral administration of raw yeast extracts. J Med Virol 2007, 79:74-83.

21. Lua LHL, Connors NK, Sainsbury F, Chuan YP, Wibowo N, Middelberg APJ: Bioengineering virus-like particles as vaccines. Biotechnol Bioeng 2014, 111:425-440. 
22. Zeltins A: Construction and characterization of virus-like particles: a review. Mol Biotechnol 2013, 53:92-107.

23. Koho T, Huhti L, Blazevic V, Nurminen K, Butcher SJ, Laurinmaki P, Kalkkinen N, Ronnholm G, Vesikari T, Hytonen VP, Kulomaa MS: Production and characterization of virus-like particles and the P domain protein of GIl.4 norovirus. J Virol Methods 2012, 179:1-7.

24. Kushnir N, Streatfield SJ, Yusibov V: Virus-like particles as a highly efficient vaccine platform: diversity of targets and production systems and advances in clinical development. Vaccine 2012, 31:58-83.

25. Xi JA, Min W, Graham DY, Estes MK: Expression, self-assembly, and antigenicity of the Norwalk virus capsid protein. J Virol 1992, 66:6527-6532.

26. Hervas-Stubbs S, Rueda P, Lopez L, Leclerc C: Insect baculoviruses strongly potentiate adaptive immune responses by inducing type I IFN (vol 178, pg 2361, 2007). J Immunol 2007, 178:6653-6653.

27. Weinacker D, Rabert C, Zepeda AB, Figueroa CA, Pessoa A, Farias JG: Applications of recombinant Pichia pastoris in the healthcare industry. Braz J Microbiol 2013, 44:1043-1048.

28. Lunsdorf H, Gurramkonda C, Adnan A, Khanna N, Rinas U: Virus-like particle production with yeast: ultrastructural and immunocytochemical insights into Pichia pastoris producing high levels of the Hepatitis B surface antigen. Microb Cell Factories 2011, 10:10.

29. Mani S, Tripathi L, Raut R, Tyagi P, Arora U, Barman T, Sood R, Galav A, Wahala W, de Silva A, Swaminathan S, Khanna N: Pichia pastoris-expressed dengue 2 envelope forms virus-like particles without Pre-membrane protein and induces high titer neutralizing antibodies. Plos One 2013, 8:e64595.

30. Tan M, Fang PG, Chachiyo T, Xia M, Huang PW, Fang ZY, Jiang W, Jiang $X$ Noroviral $P$ particle: structure, function and applications in virus-host interaction. Virology 2008, 382:115-123.

31. Tu YB, Wang YQ, Wang G, Wu JN, Liu YG, Wang SJ, Jiang CG, Cai XH: High-level expression and immunogenicity of a porcine circovirus type 2 capsid protein through codon optimization in Pichia pastoris. App/ Microbiol Biotechnol 2013, 97:2867-2875.

32. Tan M, Fang PA, Xia M, Chachiyo T, Jiang W, Jiang X: Terminal modifications of norovirus $P$ domain resulted in a new type of subviral particles, the small $P$ particles. Virology 2011, 410:345-352.

33. Tan M, Huang PW, Xia M, Fang PA, Zhong WM, McNeal M, Wei C, Jiang W, Jiang $X$ : Norovirus $P$ particle, a novel platform for vaccine development and antibody production. J Virol 2011, 85:753-764.

34. Huhti L, Tamminen K, Vesikari T, Blazevic V: Characterization and immunogenicity of norovirus capsid-derived virus-like particles purified by anion exchange chromatography. Arch Virol 2013, 158:933-942.

35. Tan $M$, Jiang $X$ : The $P$ domain of norovirus capsid protein forms a subviral particle that binds to histo-blood group antigen receptors. J Virol 2005, 79:14017-14030.

36. Uusi-Kerttula H, Tamminen K, Malm M, Vesikari T, Blazevic V: Comparison of human saliva and synthetic histo-blood group antigens usage as ligands in norovirus-like particle binding and blocking assays. Microbes Infect 2014, 16:472-480.

37. McCarter JD, Withers SG: Unequivocal identification of Asp-214 as the catalytic nucleophile of Saccharomyces cerevisiae alpha-glucosidase using 5-fluoro glycosyl fluorides. J Biol Chem 1996, 271:6889-6894.

38. Huang PW, Farkas T, Marionneau S, Zhong WM, Ruvoen-Clouet N, Morrow AL, Altaye M, Pickering LK, Newburg DS, LePendu J, Jiang X: Noroviruses bind to human $\mathrm{ABO}$, Lewis, and secretor histo-blood group antigens: Identification of 4 distinct strain-specific patterns. J Infect Dis 2003, 188:19-31.

39. Damasceno LM, Lee F, Ritter G, Old L, Batt C: High-Level Expression of a Phage Display-Derived scFv in Pichia Pastoris. In Antibody Phage Display: Methods and Protocols, Second Edition. Volume 562. Edited by Aitken R. Totowa: Humana Press Inc; 2009:225-236 [Methods in Molecular Biology].

40. Tan $M$, Jiang $X$ : Norovirus-host interaction: multi-selections by human histo-blood group antigens. Trends Microbio/ 2011, 19:382-388.

41. Huhti L, Blazevic V, Nurminen K, Koho T, Hytonen VP, Vesikari T: A comparison of methods for purification and concentration of norovirus Gll-4 capsid virus-like particles. Arch Virol 2010, 155:1855-1858.

42. Lowe AJ, Bardliving CL, Huang CJ, Teixeira LM, Damasceno LM, Anderson KA, Ritter G, Old L, Batt CA: Expression and purification of cGMP grade NY-ESO-1 for clinical trials. Biotechnol Prog 2011, 27:435-441.
43. Shi L, Sanyal G, Ni A, Luo Z, Doshna S, Wang B, Graham TL, Wang N, Volkin DB: Stabilization of human papillomavirus virus-like particles by non-ionic surfactants. J Pharm Sci 2005, 94:1538-1551.

44. Lin-Cereghino GP, Stark CM, Kim D, Chang J, Shaheen N, Poerwanto H, Agari K, Moua P, Low LK, Tran N, Huang AD, Nattestad M, Oshiro KT, Chang JW, Chavan A, Tsai JW, Lin-Cereghino J: The effect of a-mating factor secretion signal mutations on recombinant protein expression in Pichia pastoris. Gene 2013, 519:311-317.

45. Carreras-Sangrà N, Tomé-Amat J, García-Ortega L, Batt CA, Oñaderra M, Martínez-del-Pozo Á, Gavilanes JG, Lacadena J: Production and characterization of a colon cancer-specific immunotoxin based on the fungal ribotoxin a-sarcin. Protein Eng Des Sel 2012, 25:425-435.

46. Tome-Amat J, Menendez-Mendez A, Garcia-Ortega L, Batt CA, Onaderra M, Martinez-del-Pozo A, Gavilanes JG, Lacadena J: Production and characterization of scFvA33T1, an immunoRNase targeting colon cancer cells. Febs J 2012, 279:3022-3032.

47. Damasceno LM, Pla I, Chang HJ, Cohen L, Ritter G, Old L, Batt CA: An optimized fermentation process for high-level production of a single-chain Fv antibody fragment in Pichia pastoris. Protein Expr Purif 2004, 37:18-26.

48. Jewell SN, Waldo RH, Cain CC, Falkinham JO: Rapid detection of lytic antimicrobial activity against yeast and filamentous fungi. J Microbiol Methods 2002, 49:1-9.

49. Koho T, Mantyla T, Laurinmaki P, Huhti L, Butcher SJ, Vesikari T, Kulomaa MS, Hytonen VP: Purification of norovirus-like particles (VLPs) by ion exchange chromatography. J Virol Methods 2012, 181:6-11.

doi:10.1186/s12934-014-0134-z

Cite this article as: Tomé-Amat et al: Secreted production of assembled Norovirus virus-like particles from Pichia pastoris. Microbial Cell Factories 2014 13:134

\section{Submit your next manuscript to BioMed Central and take full advantage of:}

- Convenient online submission

- Thorough peer review

- No space constraints or color figure charges

- Immediate publication on acceptance

- Inclusion in PubMed, CAS, Scopus and Google Scholar

- Research which is freely available for redistribution 